\title{
BunNerdoley o pen Burden of adult neurological diseases in Odeda Area, Southwest Nigeria
}

\author{
Folajimi Morenikeji Otubogun (D) , ,2 Rufus Akinyemi, ${ }^{3,4}$ Sola Ogunniyi ${ }^{4,5}$
}

To cite: Otubogun FM, Akinyemi $R$, Ogunniyi S. Burden of adult neurological diseases in Odeda Area, Southwest Nigeria. BMJ Neurology Open 2020;2:e000062. doi:10.1136/ bmjno-2020-000062

- Additional material is published online only. To view please visit the journal online (http://dx.doi.org/10.1136/ bmino-2020-000062).

Received 30 March 2020 Revised 27 May 2020

Accepted 01 June 2020

Check for updates

(c) Author(s) (or their employer(s)) 2020. Re-use permitted under CC BY-NC. No commercial re-use. See rights and permissions. Published by BMJ.

${ }^{1}$ Internal Medicine, Olabisi Onabanjo University Teaching Hospital, Sagamu, Ogun, Nigeria ${ }^{2}$ Internal Medicine, University of Medical Sciences, Ondo, Nigeria ${ }^{3}$ Institute of Medical Research and Training, University of Ibadan College of Medicine, Ibadan, Oyo, Nigeria ${ }^{4}$ Neurology, University College Hospital Ibadan, Ibadan, Oyo, Nigeria

${ }^{5}$ Medicine, University of Ibadan College of Medicine, Ibadan, Oyo, Nigeria

Correspondence to Dr Folajimi Morenikeji Otubogun; folabogun@gmail.com

\section{ABSTRACT}

Background Few population-based studies have been conducted to determine the burden of neurological diseases in sub-Saharan Africa. A better understanding of the magnitude and impact of these disorders is pivotal to effective planning and provision of neurological services. Methods A cross-sectional survey of 2392 adults in Odeda Local Government Area, Ogun State, Southwest Nigeria was conducted between May and June 2015. Trained non-medical interviewers administered a screening instrument designed to measure the prevalence of neurological diseases and disability, while positive responders were subsequently examined by neurologists. Diagnoses were made clinically according to wellestablished criteria.

Results The mean age of respondents was $37.2 \pm 16.1$ years. A total of 842 cases of neurological diseases/ disability were diagnosed in 815 individuals ( 26 individuals with more than one disorder). The all-cause neurological morbidity rate was 352 per 1000 , while the crude prevalence rates of common neurological disorders were 304.3 per 1000 for primary headaches, 16.3 per 1000 for tropical ataxic neuropathy, 7.11 per 1000 for stroke, 5.85 per 1000 for essential tremor and 4.18 per 1000 for Parkinson's disease. Neurological years lost due to disability was 2806.18 per 100000 .

Conclusion This study provides evidence of a high neurological disease burden within the communities surveyed, which may be representative of Southwest Nigeria. In comparison with findings from previous studies within the same region, this report suggests a persistence of toxiconutritional disorders and postinfectious neurological sequelae on one hand and increased prevalence of non-communicable neurological disorders such as stroke and Parkinson's disease.

\section{BACKGROUND}

Neurological disorders are common and costly, accounting for $6.3 \%$ of the global burden of diseases and affecting over onebillion people. ${ }^{1}$ Cerebrovascular disease is the second leading cause of mortality globally, while migraine is one of the three most prevalent conditions in the world. ${ }^{2}$ Despite the huge public health significance of these diseases, their global impact is often largely underestimated. ${ }^{3}$ The Global Initiative on Neurology and Public Health and international surveys of country resources have shown a paucity of information on the burden of neurological disorders globally and particularly in the sub-Saharan Africa (SSA) region. ${ }^{4-6}$ Available neuroepidemiological data from countries in the SSA region such as Nigeria are often derived from hospitalbased studies, whereas results from previously conducted population-based surveys may require substantial updates due to changes in population structure, lifestyle and epidemiological transition. ${ }^{7-9}$

\section{Study objective}

The objective was to determine the prevalence of neurological disorders in adult residents of Odeda Local Government Area (OLGA) of Ogun State in Southwest Nigeria.

\section{METHODS}

\section{Study design}

This was a descriptive, two-phase, crosssectional study conducted between May and June 2015. The first phase involved application of a screening tool, while the second phase entailed neurological examination of positive responders identified in the first phase. Non-medical interviewers were recruited and trained to apply the screening instrument, while neurologists performed neurological examinations on identified positive participants.

\section{Study setting}

This survey was conducted in communities of OLGA, one of the 10 local government areas of Ogun State, Southwest Nigeria, with a population of 109522. This administrative unit is located between $7^{\circ} 13^{\prime} 00^{\prime \prime}-7^{\circ} 21^{\prime} 66^{\prime \prime}$ north and $3^{\circ} 31^{\prime} 00^{\prime \prime}-3.5^{\circ} 16^{\prime} 67^{\prime \prime}$ east and has a land mass of $1560 \mathrm{~km}^{2}$. OLGA comprised both urban and rural communities, while its residents are predominantly Yoruba (Egba dialect). The economy is mainly agrarian, with major food crops being cassava, yam, cocoyam, plantain, maize and vegetables, and major cash crop cocoa. However, other economic activities include quarrying, trading and artisanship. 
Christianity, Islam and traditional religion are the major religions.

The study area's health service arrangements consist of primary health centres, one in each ward and staffed by nurses, and community health extension workers. Private clinics also filled the gap for primary healthcare. Secondary level healthcare is obtained from general hospitals, while tertiary level care is available at the Federal Medical Centre, Abeokuta. At the time of this study, neurological manpower was limited to two neurologists and two specialty registrars in neurology. Electroencephalography and CT were available within the study area, whereas MRI and neurosurgical support were accessed from neighbouring states, which were $66.3-123.7 \mathrm{~km}$ away.

\section{Inclusion criteria}

Inclusion criteria included consenting adults aged 18 years and above at study onset (1 May 2015) and residents within OLGA for the preceding 6 months.

\section{Sampling technique}

A two-stage cluster sampling technique was employed. In the first stage, the smaller administrative units of OLGA were classified into predominantly urban/semiurban and rural based on information provided by the local health authority. A ballot was done to pick one of two urban/ semiurban wards and two of eight rural wards: Obantoko ward for urban/semiurban and Odeda and Alabata wards for the rural wards.

Cluster sampling size formula for descriptive survey was used and calculated as the following:

$$
n=g \times z^{2} \times p \times q / d^{2}
$$

$\mathrm{n}$ : minimum sample size; g: design effect $=2$; $\mathrm{z}$ : standard normal deviate $=1.96$ at $95 \%$ confidence level; p: estimated prevalence $=5.3 \%$ (crude point prevalence of least prevalent condition-migraine in a previous survey) ${ }^{1}$; q: $1-\mathrm{p} ; \mathrm{d}$ : degree of precision $=2 \%$.

$$
n=2 \times \frac{1.96^{2} \times 0.053 \times 0.947}{0.02^{2}}
$$

\section{$\mathrm{n}=964.06$}

$\mathrm{n}=964$

Six clusters of at least 161 respondents each (two clusters from each ward) were proposed. However, the sampled population exceeded the calculated minimum sample size due to the eagerness of residents within the selected clusters to take part in the screening.

\section{Screening instrument}

The screening instrument to measure the prevalence of neurological disability in resource-poor setting developed by Bower $e t a l^{10}$ was used (online supplementary appendix 1 ). This tool has 24 history questions and 16 examination tasks and has been validated in two SSA countries and found to have sensitivity and specificity of $100 \%$ and $82.4 \%$, respectively. ${ }^{11}$ This instrument was translated to Yoruba language following standard procedures for ease of administration to the mainly Yoruba-speaking study population. ${ }^{12}$

\section{Study protocol}

Permission was obtained from the OLGA health authority and community gatekeepers-the heads of various communities and traditional rulers/village heads.

Residential houses were visited in each selected cluster and consent was obtained to speak with the head of the households, which was usually the oldest individual or any adult in his/her absence. The number of family units living within the house and a listing of individuals 18 years or older were obtained. This provided the base population for the study. Only adults that were present at the single visits were screened for neurological disorders.

Interviews were conducted in the local language (Yoruba) and English language. Survey sites were located and boundaries identified with the help of OLGA primary health staff and local people. Five non-medical interviewers were recruited and trained on the use of the screening instrument at the neurology outpatient clinic of Federal Medical Centre, Abeokuta, and an interobserver agreement kappa value of 0.95 was achieved.

Phase 1 screening was in three steps. The initial step included allocation of study identification numbers and collection of sociodemographic data such as age (verified by birth records or historical events), sex, tribe, occupation, marital status and highest educational attainment entered into a pro forma. ${ }^{13}$ The second step consisted of 22 history questions, while the third step entailed performance of 16 simple tasks. An individual was considered to 'screen positive' if at least one history question and/or one examination task was positive.

In phase 2, positive responders were further evaluated by neurologists who took focused histories and performed neurological examinations, after which respondents were classified with or without a neurological disease or disability. Subjects without prior neurological diagnoses were counselled by the investigators on the nature of the conditions and importance of accessing further relevant clinical and follow-up care at the neurology clinic of the Federal Medical Centre, Abeokuta. However, those with prior neurological diagnoses and care plan were provided with appropriate health information based on specific needs.

\section{Case ascertainment}

Diagnoses made were predominantly clinical except for half of identified people with epilepsy in whom interictal electroencephalograms were completed at the neurophysiology unit of Federal Medical Centre, Abeokuta (the remaining half either did not consent or were unable to travel).

\section{Data management}

Anonymised data were entered into Microsoft Excel for cleaning and were transferred to the Statistical Package for the Social Sciences (SPSS) V.20 for analysis. Sociodemographic variables were computed and presented as mean $\pm \mathrm{SD}$ for continuous variables and frequencies and percentages for categorical variables. Crude 


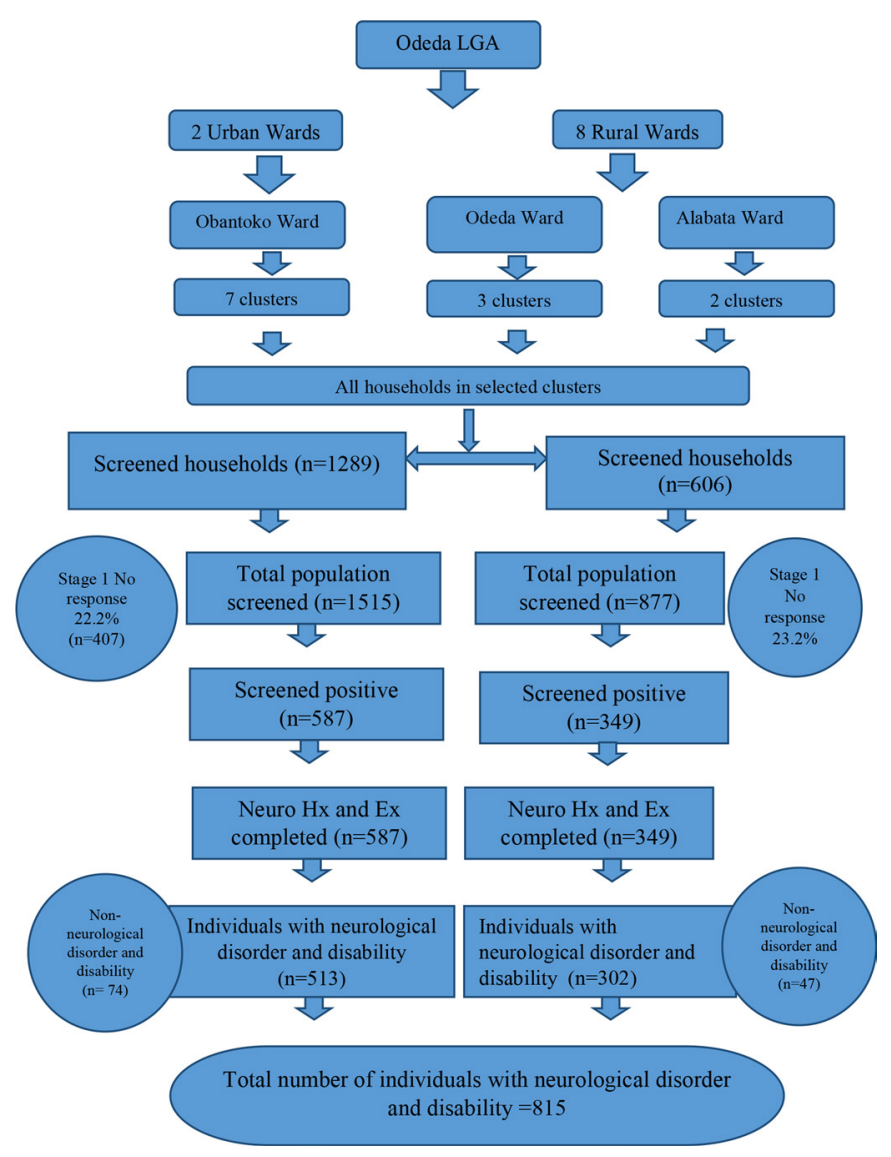

Figure 1 Study flow chart. Ex, examination; Hx, history; LGA, Local Government Area.

prevalence rates of neurological diseases and disabilities were calculated and presented as period prevalence rates. Pearson's $\chi^{2}$ test was used to determine statistically significant differences in prevalence rates of neurological diseases between subgroups, while Fisher's exact test was used instead of Pearson's $\chi^{2}$ test for two-by-two tables with cells with frequency less than five. For variables with normal distribution, comparison between groups was performed using independent t-test. A 5\% significance level ( $p$ value less than or equal to 0.05 ) was considered significant.

\section{RESULTS \\ Outcome}

A total of 1891 households were enumerated, with a base population of 3064 aged 18 years and above (figure 1). The response rate was $78.0 \%(\mathrm{~N}=2392)$. A total of 2392 adults were screened, $1470(61.5 \%)$ were women and 922 $(38.5 \%)$ were men. The mean age of respondents was $37.2 \pm 16.1$ years, while the age range was $18-114$ years. The largest age group was $18-29$ years $(39.4 \%)$, while $13.3 \%$ of the study population were 60 years or older (table 1 ).

The majority of participants in this study were of Yoruba ethnicity $(86.4 \%)$ and were literate $(77.4 \%)$. The first phase of screening identified 936 positive responders (39.1\% population), while the second phase yielded neurological disorder and disability diagnoses in 815 people (842 cases of neurological disorders and disability were identified in 815 people, with 25 people with two cases and 1 person with three cases). One hundred and twenty-one individuals had non-neurological diseases and disabilities (eg, syncope, osteoarthritis, cataracts and musculoskeletal pain) and were excluded in the final classification and analyses.

\begin{tabular}{lllll}
\hline Table 1 & Study population & & & \\
\hline & $\begin{array}{l}\text { Age groups } \\
\text { (years) }\end{array}$ & Male (\% total population) & $\begin{array}{l}\text { Female (\% total } \\
\text { population) }\end{array}$ & $\begin{array}{l}\text { Total (\% total } \\
\text { population=2392) }\end{array}$ \\
\hline Gender & $18-29$ & $373(15.5)$ & $571(23.8)$ & $944(39.4)$ \\
& $30-39$ & $229(9.5)$ & $345(14.4)$ & $574(23.9)$ \\
& $40-49$ & $125(5.2)$ & $226(9.4)$ & $351(14.6)$ \\
& $50-59$ & $62(2.5)$ & $141(5.8)$ & $203(8.4)$ \\
& $60-69$ & $71(2.9)$ & $101(4.2)$ & $172(7.1)$ \\
& $70-79$ & $42(1.7)$ & $54(2.2)$ & $96(4.0)$ \\
& $\geq 80$ & $20(0.8)$ & $32(1.3)$ & $52(2.2)$ \\
\hline Location & Urban (\% total & & Total (\% total \\
& Age groups & population) & Rural (\% total population) population=2392) \\
& $18-29$ & $653(27.2)$ & $291(12.1)$ & $944(39.4)$ \\
& $30-39$ & $376(15.7)$ & $198(8.2)$ & $574(23.9)$ \\
& $40-49$ & $205(8.5)$ & $144(6.0)$ & $351(14.6)$ \\
& $50-59$ & $118(4.9)$ & $85(3.5)$ & $203(8.4)$ \\
& $60-69$ & $86(3.5)$ & $86(3.5)$ & $172(7.1)$ \\
& $70-79$ & $49(2.0)$ & $47(1.9)$ & $96(4.0)$ \\
& $\geq 80$ & $24(1.0)$ & $28(1.1)$ & $52(2.1)$ \\
\hline
\end{tabular}




\section{Prevalence of neurological diseases and disability}

Eight hundred and forty-two cases of neurological diseases and disability were diagnosed in 815 individuals, with a composite crude prevalence rate of 352 per 1000 (95\% CI 333.1 to 352.0 per 1000) (table 2).

Primary headache disorders constituted the most prevalent neurological disorder in this survey $(n=729 ; 30.5 \%$ of study population). Infrequent episodic tension headache was excluded from this survey due to its universality and little or no medical importance. Only frequent episodic and chronic tension-type headaches were diagnosed and analysed, with $704(62.8 \%)$ and 14 (71.4\%) women, respectively.

Tropical ataxic neuropathy (TAN) was the second most diagnosed condition in this cohort (16.3 per 1000, 95\% CI 11.9 to 22.2 per 1000), while movement disorders (10.5 per $1000,95 \%$ CI 7.1 to 15.4 per 1000 ) and stroke (7.11 per $1000,95 \%$ CI 4.4 to 11.3 per 1000 ) were the third and fourth leading causes of neurological disease and disability.

Women had higher prevalence of migraine (men 5.4 per $1000,95 \%$ CI 2.3 to 12.6 per 1000 ; women 11.5 per $1000,95 \%$ CI 7.3 to 18.5 per 1000 ), while men had significantly higher neurological morbidity from movement disorders (men 18.4 per 1000, 95\% CI 11.5 to 29.3 per 1000; women 5.4 per $1000,95 \%$ CI 2.7 to 10.6 per 1000).

The highest observed age-specific all-cause neurological morbidity in this study was in the eighth decade, while smaller peaks in the sixth decade for both sexes and in the 18-29 years age group in women alone were noted (table 3 ).

The peak age-specific morbidity in the $70-79$ years age group was due to higher prevalence rates for movement disorders, stroke and TAN.

\section{DISCUSSION}

Nigeria in 2015, when this study was conducted, was projected to have had $51.5 \%$ of its population within the $15-59$ years age group, whereas only $4.5 \%$ of the entire nation were 60 years and older. ${ }^{14}$ During the same period, the median age was estimated to be 17.9 years. The younger overall age of our study population is consistent with Nigeria's quite youthful demographic profile.

However, in comparison with an earlier neuroepidemiological survey in Igbo-Ora, Southwest Nigeria, where the entire population was screened, this study had a higher proportion of older subjects $(20 \%$ and $6 \%$ above 30 years and 60 years in Igbo-Ora survey; $60.5 \%$ and $13.4 \%$ in populations of over 30 years and 60 years, respectively, in OLGA survey). ${ }^{7}$ Improving standards of living and better access to immunisation and healthcare may account for the trend towards longer lifespan. Thus, higher prevalence rates of Parkinson's disease (PD), dementia and strokes were anticipated.

There was a female preponderance among respondents $(61.5 \%)$, which may be due to women working from or nearer their homes, thereby being more accessible and available for participation in this study. ${ }^{15}$

A composite neurological morbidity prevalence rate of 352 per 1000 in OLGA depicts a higher neurological disease and disability burden in contrast to Igbo-Ora, Southwest Nigeria (64.5 per 1000) and Bangalore, India (9.84-40.7 per 1000). ${ }^{716}$ Aside from the different base population, our inclusion of primary headache disorders-a veritable cause of neurological morbidity-may explain the higher prevalence rates in OLGA.

\section{Headaches}

Tension-type headache was the most common disorder in this study and consistent with the 2011 Global Burden of Disease prevalence estimate of 1.6 billion people living with tension-type headaches. ${ }^{6}$ However, a lower prevalence of migraine $(<1 \%)$ was obtained in this survey, compared with global estimates of $3 \%-7 \%$ and local estimates of $5.3 \%-18.9 \% .^{17-22}$

The older age of this study population may be a factor, as previously reported by Osuntokun et $a l^{7}$ where the highest age-specific prevalence was in the first decade of life.

\section{Epilepsy}

A lower crude prevalence rate of 2.93 per 1000 was found, compared with global estimates (4-8 per 1000) and local studies (4.1-28 per 1000) ${ }^{23-25}$ A key factor may be the exclusion of children, who have higher prevalence rate for epilepsy, while more widespread immunisation coverage, increasing knowledge, prevention and treatment of febrile convulsions are possible causes of lower prevalence of epilepsy.

\section{Stroke}

Similarly high prevalence of stroke survivors has been reported in South-South Nigeria (8.51 per 1000 and 14.6 per 1000). ${ }^{2627}$ On the other hand, there have also been lower rates observed in North Central Nigeria (1.31 per $1000) .{ }^{28}$ This wide variation may be due to differences in availability and accessibility of acute stroke care services, health-seeking behaviour and case fatality rates.

\section{Tropical ataxic neuropathy}

TAN diagnosis required the presence of two or more of optic disc pallor, impairment in Rinne's test, impairment of pain, fine touch and vibratory perception above the malleoli, and impaired tandem gait. ${ }^{29}$

This study's prevalence of 16.3 per 1000 for TAN in the adult population of $\mathrm{OLGA}^{29}$ appeared to be significantly higher than previously described in Igbo-Ora by Osuntokun. ${ }^{7}$ However, a comparison of the age-specific prevalence rates suggested otherwise. Osuntokun et al reported a crude prevalence of 1.85 per 1000 for the entire predominantly young study population but much higher age-specific prevalence rates in the sixth decade at 7.29 per 1000 and ninth decade at 29.7 per 1000 . Thus, it would appear that TAN still persists in an endemic form as earlier reported by Oluwole $e t a \hat{l}^{30}$ in Ososa, another 


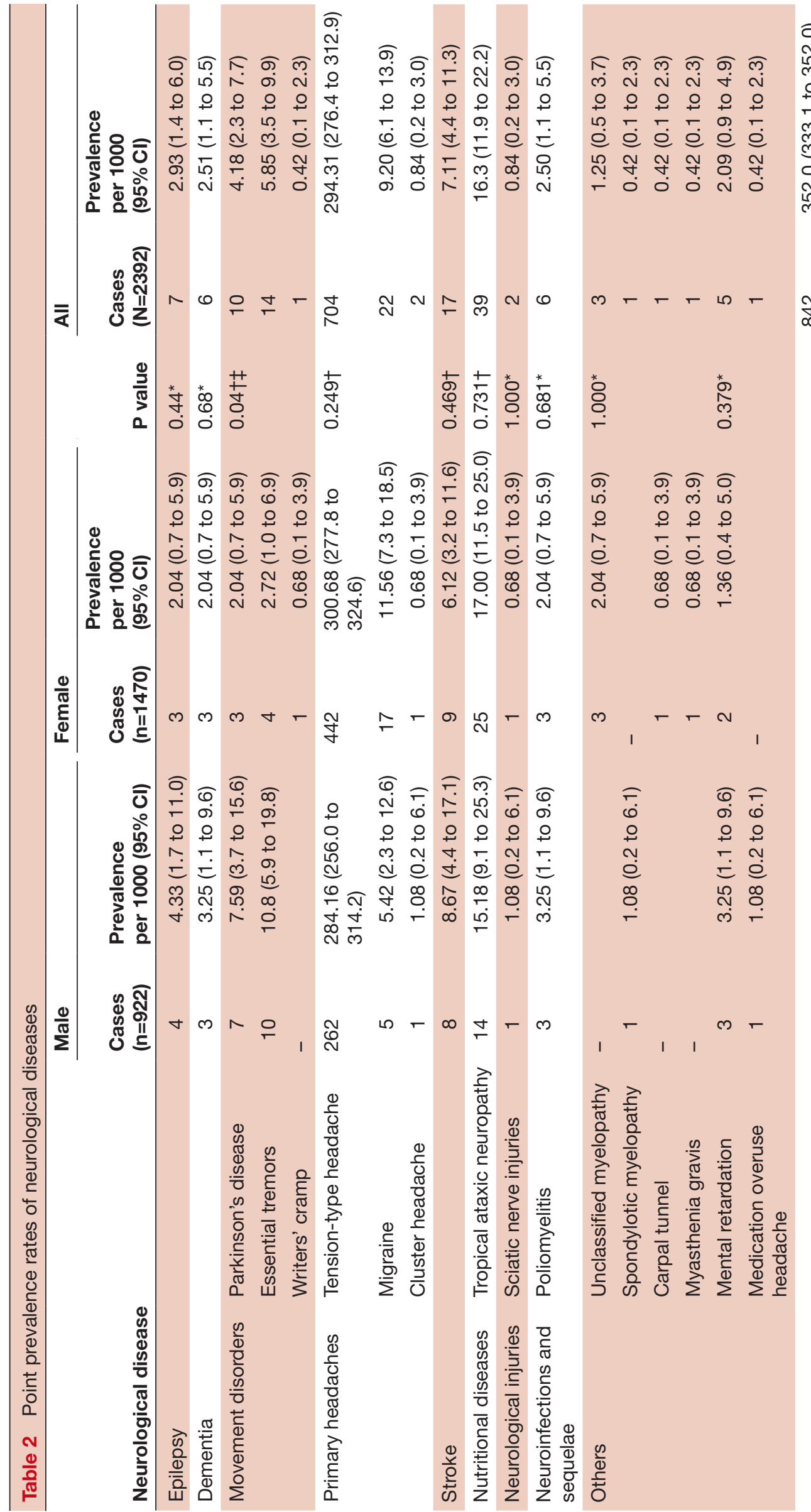

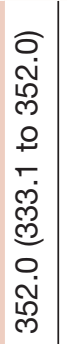


Table 3 Age specific all-cause neurological morbidity

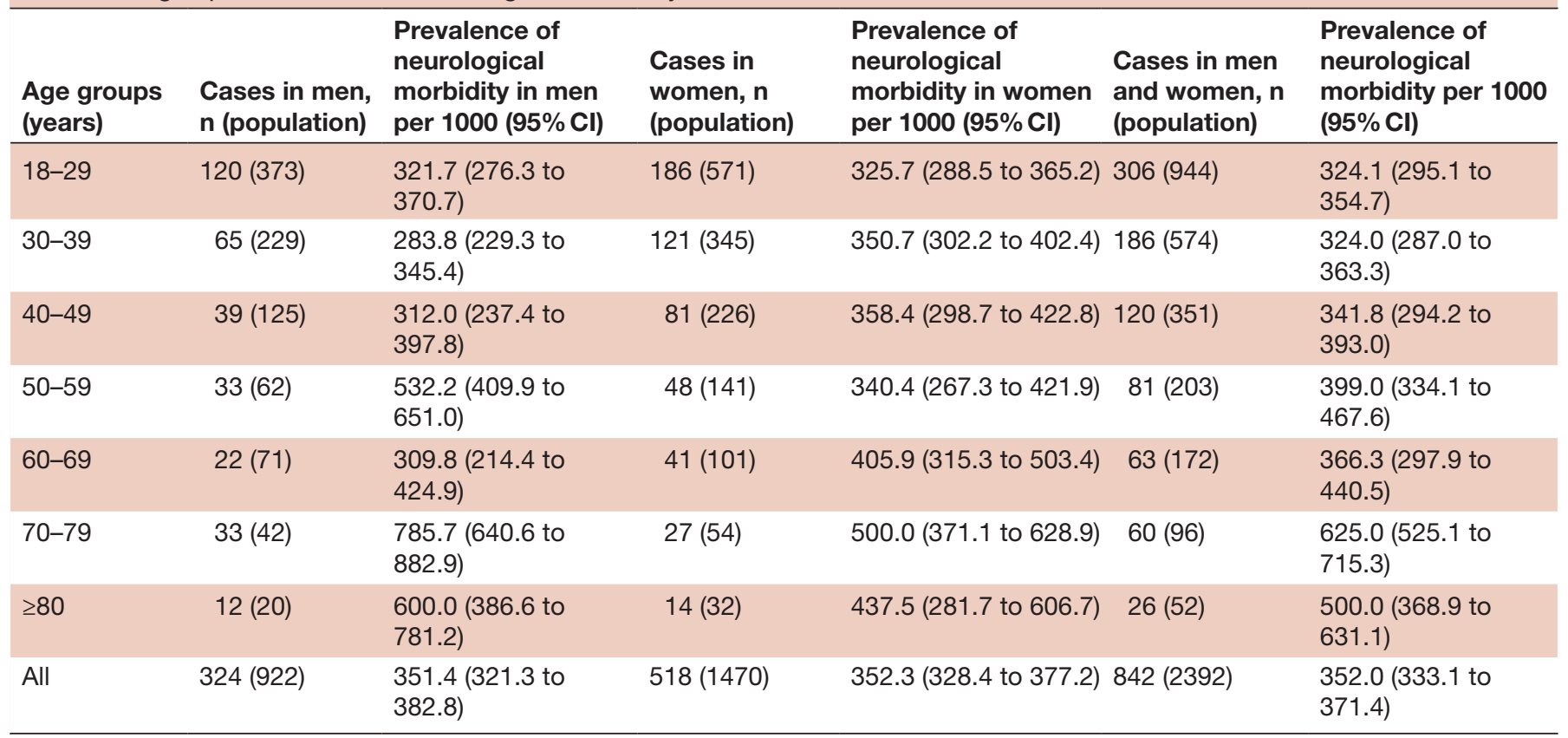

Southwest Nigerian town where a prevalence of $6 \%$ was reported.

\section{Movement disorders}

Essential tremor was the most prevalent movement disorder identified in this work, being much higher than in earlier reports by Osuntokun et $a l^{30}$ in Igbo-Ora and Haimanot $e t a \hat{l}^{11}$ in central Ethiopia, but closer to the prevalence rate reported in Lagos by Okubadejo et al. ${ }^{32}$ The older age of study subjects is likely to account for a higher prevalence rate compared with earlier works as it is well established that incidence and prevalence of essential tremor rise with ageing. ${ }^{33}$

The crude prevalence of PD was much higher than global estimates of 1-2 per 1000 because only adults 18 years or older formed the base population rather than the entire population as denominator. Nevertheless, this finding suggests increased prevalence of PD when compared with a study conducted decades ago in Igbo-Ora for the prevalence of PD in individuals older than 39 years. ${ }^{34}$ Increasing average life expectancy as well as increasing awareness of PD and availability of medications for PD with accompanying global decline in PD mortality may be responsible for the increased prevalence. $^{35-37}$

\section{Strengths of the study}

This work was population-based with the advantage of eliminating the 'iceberg' phenomenon typical of hospital-based studies. All types of neurological diseases were screened for, rather than a specific disease entity. Thus this study provided a panoramic view of neurological disease burden in community studies.

\section{Study limitations}

With regard to case ascertainment, neuroimaging could have increased accuracy and reliability of diagnoses, especially for stroke diagnosis and exclusion of other causes of headaches. However, the Questionnaire for Verifying Stroke-Free Status (100\% sensitivity, $86 \%$ specificity) was used in order to increase the sensitivity of stroke diagnosis in the survey, ${ }^{38}$ while headache diagnoses and classification were based on the International Classification of Headache Disorders-3. ${ }^{18}$

With regard to base population, a much larger base population would have increased the generalisability of the findings.

\section{CONCLUSIONS}

This study provides evidence of a high neurological disease burden within the communities surveyed, which may be representative of Southwest Nigeria. Compared with findings from previous studies within the same region, this report suggests a persistence of toxiconutritional disorders and postinfectious neurological sequelae on one hand and increased prevalence of non-communicable neurological disorders such as stroke and PD. Faced with this rising trend in neurological morbidity, there is a need to increase delivery and access to neurological care services as well as health education of local communities.

Acknowledgements The authors would like to acknowledge the translators, Mayowa Aderibigbe and Damilola Abiola; the research assistants, Gbemisola, Bimpe, Sumbo, Kenny and Kike; and statistician Dr Joseph Yaria.

Contributors FMO, RA and SO contributed to the design and implementation of the research, analysis of the results, and writing of the manuscript. All authors have read and approved the manuscript. 
Funding The authors have not declared a specific grant for this research from any funding agency in the public, commercial or not-for-profit sectors.

Competing interests None declared.

Patient consent for publication Not required.

Ethics approval Subjects (or their parents or guardians) gave their written informed consent. The study protocol (FMCA/470/HREC/09/2014) was approved by Federal Medical Centre, Abeokuta Health Research Ethics Committee (NREC/08/05/2010-2012/15).

Provenance and peer review Not commissioned; externally peer reviewed.

Data availability statement Data are available upon reasonable request.

Open access This is an open access article distributed in accordance with the Creative Commons Attribution Non Commercial (CC BY-NC 4.0) license, which permits others to distribute, remix, adapt, build upon this work non-commercially, and license their derivative works on different terms, provided the original work is properly cited, appropriate credit is given, any changes made indicated, and the use is non-commercial. See: http://creativecommons.org/licenses/by-nc/4.0/.

ORCID iD

Folajimi Morenikeji Otubogun http://orcid.org/0000-0001-9753-4532

\section{REFERENCES}

1 Dua T, Cumbrera MG, Mathers C, et al. Global burden of neurological disorders: estimates and projections. In: Neurological disorders: public health challenges. Geneva, Switzerland: World Health Organization, 2006: 27-39.

2 Mathers C, Fat DM, Boerma JT. Disease incidence, prevalence and disability. In: The global burden of disease: 2004 update. Geneva, Switzerland: World Health Organization, 2008: 28-36.

3 Murray CJ, Lopez AD. Quantifying the burden of disease and injury attributable to ten major risk factors. the global burden of disease: a comprehensive assessment of mortality and disability from diseases, injuries, and risk factors in 1990 and projected to 2020. Cambridge, MA: Harvard School of Public health on behalf of the World Health Organization and the World Bank, 1996 (Global Burden of Disease and Injury series, Vol.1): 295-324.

4 Janca A, Prilipko L. The world Health organization's global initiative on neurology and public health. J Neurol Sci 1997;145:1-2.

5 World Health Organization. Atlas : Country Resources for

Neurological Disorders 2004. Geneva: World Health Organization and World Federation of Neurology, 2004.

6 Vos T, Barber RM, Bell B, et al. Global, regional, and national incidence, prevalence, and years lived with disability for 301 acute and chronic diseases and injuries in 188 countries, 1990-2013: a systematic analysis for the global burden of disease study 2013 . The Lancet 2015;386:743-800.

7 Osuntokun BO, Adeuja AOG, Schoenberg BS, et al. Neurological disorders in Nigerian Africans: a community-based study. Acta Neurol Scand 1987;75:13-21.

8 Ogunniyi A, Baiyewu O, Gureje O, et al. Epidemiology of dementia in Nigeria: results from the Indianapolis-Ibadan study. European Journal of Neurology 2000;7:485-90.

9 Danesi MA, Okubadejo NU, Ojini FI, et al. Incidence and 30-day case fatality rate of first-ever stroke in urban Nigeria: the prospective community based epidemiology of stroke in Lagos (EPISIL) phase II results. J Neurol Sci 2013;331:43-7.

10 Bower JH, Howlett W, Maro VP, et al. A screening instrument to measure the prevalence of neurological disability in resource-poor settings. Neuroepidemiology 2009;32:313-20.

11 Bower JH, Mwendo E, Walker R, et al. Validity of a screening instrument for neurologic disability in resource-poor African communities. J Neurol Sci 2012;320:52-5.

12 World Health Organization. Process of translation and adaptation of instruments [Internet]. New York, NY: WHO. Available: http:// www.who.int/substance_abuse/research_tools/translation/en.2020 [Accessed 19 May 2020].

13 Ogunniyi A, Osuntokun BO. Determination of ages of elderly Nigerians through historical events: validation of Ajayi-Igun 1963 listing. West Afr J Med 1993;12:189-90.
14 Nations U. World population prospects: the 2015 revision. United Nations Econ Soc Aff 2015;33:1-66.

15 Fanning Madden J, Madden JF. Why women work closer to home. Urban Stud 1981;18:181-94.

16 Gourie-Devi M, Gururaj G, Satishchandra P, et al. Prevalence of neurological disorders in Bangalore, India: a communitybased study with a comparison between urban and rural areas. Neuroepidemiology 2004;23:261-8.

17 Steiner TJ, World Headache Alliance. Lifting the burden: the global campaign against headache. Lancet Neurol 2004;3:204-5.

18 Headache Classification Committee of the International Headache Society (IHS). The International classification of headache disorders, 3rd edition. Cephalalgia 2018;38:1-211.

19 Ezeala-Adikaibe BA, Onyekonwu C, Okudo G, et al. Prevalence of primary headaches in an urban slum in Enugu South East Nigeria: a door-to-door survey. Headache 2014;54:1601-10.

20 Oshinaike O, Ojo O, Okubadejo N, et al. Primary headache disorders at a tertiary health facility in Lagos, Nigeria: prevalence and consultation patterns. Biomed Res Int 2014;2014:1-5.

21 Ogunyemi AO. Prevalence of headache among Nigerian university students. Headache 1984;24:127-30.

22 Woldeamanuel YW, Andreou AP, Cowan RP. Prevalence of migraine headache and its weight on neurological burden in Africa: a 43-year systematic review and meta-analysis of community-based studies. $J$ Neurol Sci 2014;342:1-15.

23 Banerjee PN, Hauser WA. Incidence and prevalence. In: Engel J, Pedley TA, Aicardi T, eds. Epilepsy: a comprehensive textbook. 2nd edn. Lippincott Williams \& Wilkins, 2008: 45-56.

24 Osakwe C, Otte WM, Alo C. Epilepsy prevalence, potential causes and social beliefs in Ebonyi state and Benue state, Nigeria. Epilepsy Res 2014;108:316-26.

25 Nwani PO, Nwosu MC, Asomugha LA, et al. Epidemiology of active epilepsy in a suburban community in Southeast Nigeria: a door-todoor survey. Niger J Clin Pract 2015;18:527.

26 Onwuchekwa AC, Tobin-West C, Babatunde S. Prevalence and risk factors for stroke in an adult population in a rural community in the niger delta, South-South Nigeria. J Stroke Cerebrovasc Dis 2014;23:505-10.

27 Ezejimofor MC, Uthman OA, Maduka O, et al. Stroke survivors in Nigeria: a door-to-door prevalence survey from the niger delta region. J Neurol Sci 2017;372:262-9.

28 Sanya EO, Desalu OO, Adepoju F, et al. Prevalence of stroke in three semi-urban communities in middle-belt region of Nigeria: a door to door survey. Pan African Medical Journal 2015;20.

29 Otubogun FM, Akinyemi RO, Ogunniyi AO. Tropical ataxic neuropathy: findings of a neuroepidemiological survey of Odeda, Southwest Nigeria. J Neurol Sci 2019;405:116434.

30 Oluwole OSA, Onabolu A, Link H. Persistence of tropical ataxic neuropathy in a Nigerian community. Journal of Neurology, Neurosurgery Psychiatry 2000;69:96-101.

31 Haimanot RT, Abebe M, Mariam AG, et al. Community-Based study of neurological disorders in Ethiopia: development of a screening instrument. Ethiop Med J 1990;28:123-37.

32 Okubadejo NU, Bankole IA, Ojo OO, et al. Prevalence of essential tremor in urban Lagos, Nigeria: a door-to-door community-based study. BMC Neurol 2012;12:110.

33 Louis ED, Thawani SP, Andrews HF. Prevalence of essential tremor in a multiethnic, community-based study in Northern Manhattan, New York, N.Y. Neuroepidemiology 2009;32:208-14.

34 Schoenberg BS, Osuntokun BO, G. Adeuja AO, et al. Comparison of the prevalence of Parkinson's disease in black populations in the rural United States and in rural Nigeria: door-to-door community studies. Neurology 1988;38:645.

35 Ogunniyi A. Treatment of parkinsonian syndromes in developing countries. Afr J Med Med Sci 1996;26:101-3.

36 Mylne AQN, Griffiths C, Rooney C, et al. Trends in Parkinson's disease related mortality in England and Wales, 1993-2006. European Journal of Neurology 2009;16:1010-6.

37 Akinyemi RO. Epidemiology of parkinsonism and Parkinson's disease in sub-Saharan Africa: Nigerian profile. J Neurosci Rural Pract 2012;3:233-4.

38 Meschia JF, Brott TG, Chukwudelunzu FE, et al. Verifying the stroke-free phenotype by structured telephone interview. Stroke 2000;31:1076-80. 